\title{
J-DEPACE
}

J-DEPACE, Volume 3, Nomor 2, Desember 2020, Hal 256-263

Tersedia online di :http://jurnal.lpmiunvic.ac.id/index.php/jpkm

\section{SMART IS AN ART: MEMBENTUK GENERASI MUDA MELEK BACA DAN TEKNOLOGI PADA RT 006/RW 001 KPR PUTRA RESIDENCE}

\author{
Lulu Jola Uktolseja ${ }^{1 *}$, Melda Agnes Manuhutu, S.Kom., M.Cs \\ Dr. Tagor Manurung, SE., MM, Sherly Gaspersz, S.Pd., M.Pd, Natasya Virginia Leuwol, S.Si., \\ M.Si, Dr. Roximelsen Suripatty, SH., MH., M.Kn, Jalmijn Tindage, S.Sos., MM \\ Universitas Victory Sorong \\ ${ }^{1}$ lulujola39@gmail.com, melda.a.manuhutu@gmail.com, tagormanurung24031963@gmail.com, \\ sherlygaspersz9@gmail.com, natasya.leuwol@gmail.com, \\ roximelsensuripatty@unvicsorong.ac.id, jalmijn@unvicsorong.ac.id
}

\begin{abstract}
ABSTRAK
Pandemi Covid-19 yang telah terjadi sejak 2019 menyebabkan begitu banyak permasalahan yang timbul. Salah satu sektor yang sangat terdampak adalah sektor pendidikan. Menyaksikan tantangan dunia pendidikan saat ini, Smart is an Art hadir pada RT 006/RW 001 KPR Putra Residence dengan kegiatan berjudul: Membentuk Generasi Muda Melek Baca Dan Teknologi. Kegiatan ini dilatarbelakangi oleh keinginan Tim untuk membantu anak-anak mengenal teknologi komputer dan juga gemar membaca melalui buku-buku yang disediakan oleh Tim. Adapun tujuan yang ingin dicapai dari pelaksanaan kegiatan ini adalah sebagai berikut: a) Untuk membantu para peserta memahami pentingnya membaca dan teknologi; b) Untuk memberikan pembelajaran yang menarik dan menyenangkan. Pelaksanaan kegiatan Smart is An Art diselenggarakan dengan santai dan menyenangkan. Hal ini dibuat dengan tujuan memberikan perasaan rileks tanpa beban belajar bagi para peserta. Kegiatan ini dilaksanakan pada 2 (dua) rumah warga di KPR Putra Residence dengan jumlah 20 peserta. Kegiatan dibuka dengan Doa, penyampaian teknis kegiatan kemudian pemaparan materi. Adapun pemaparan materi adalah praktek pengenalan komputer, tablet dan handphone, serta pengenalan buku- buku bacaan. Pemateri juga membaca cerita, memutarkan video cerita dan evaluasi cerita bersama dengan peserta. Manfaat dari pelaksanaan kegiatan ini adalah untuk melatih peserta disiplin belajar selama masa pandemi, meningkatkan ketertarikan terhadap buku bacaan dan teknologi.
\end{abstract}

Kata kunci: media pembelajaran, buku, teknologi 


\begin{abstract}
The Covid-19 pandemic that has occurred since 2019 has caused so many problems that have arisen. One of the most important sectors is the education sector. Witnessing the challenges of today's education world, Smart is an Art was present at RT 006/RW 001 KPR Putra Residence with an activity entitled: Forming a Young Generation to Read and Technology Literate This activity was motivated by the team's desire to help children get to know computer technology and also love to read through the books provided by Tim. The objectives to be achieved from the implementation of this activity are as follows: a) To help participants understand the importance of reading and technology; b) To provide interesting and fun learning. The implementation of Smart is An Art activities was carried out in a relaxed and fun way. This is made with the aim of providing a relaxed feeling without the burden of learning for the participants. This activity was carried out in 2 (two) residents' houses at KPR Putra Residence with a total of 20 participants. The activity was opened with a prayer, the implementation of the activity and then the presentation of the material. The presentation of the material is the practice of introducing computers, tablets and cellphones, as well as the introduction of reading books. The presenters also read stories, played video stories and evaluated together with the participants. The benefits of implementing this activity are to train participants to learn during the pandemic, increase interest in reading books and technology.
\end{abstract}

Keywords: learning media, books, technology

\title{
1. PENDAHULUAN
}

Pandemi Covid-19 yang telah terjadi sejak 2019 menyebabkan begitu banyak permasalahan yang timbul. Salah satu sektor yang sangat terdampak adalah sektor pendidikan. Jutaan anak usia sekolah terpaksa harus menikmati Proses Belajar Mengajar (PBM) secara daring atau dalam jaringan. PBM yang biasanya dilakukan dengan tatap muka secara langsung harus dilakukan melalui tatap maya, untuk membatasi perjumpaan secara langsung sehingga dapat memperbesar kesempatan pencegahan Covid-19.

Beberapa kelompok anak sekolah tersebut mampu beradaptasi dengan pola pembelajaran baru tersebut, didukung fasilitas pendidikan yang memadai di rumah seperti laptop, tablet ataupun handphone. Namun, adapula kelompok anak sekolah lainnya yang sulit menyesuaikan diri karena keterbatasan fasilitas belajar. Pada akhirnya, tak jarang ditemui anak-anak yang malah tidak belajar sama sekali. Lalu, yang muncul adalah kekhawatiran tentang ilmu pengetahuan yang merupakan sumber kehidupan masa depan bagi mereka.

Melihat fenomena yang terjadi tersebut maka dibutuhkan gerak langkah setiap linih 
masyarakat untuk memastikan sektor pendidikan tidak akan lumpuh. Selain pendidikan formal yang dilaksanakan dari pihak sekolah melalui pemanfaatan video conference, Whatsapp Group ataupun modul belajar, kehadiran pihak non formal lainnya seperti lembaga independen masyarakat untuk turut terlibat menyokong pendidikan Indonesia dalam tantangan Covid-19.

Smart is an Art merupakan sebuah Kegiatan Pengabdian Kepada Masyarakat yang sustainable dan telah dilaksanakan sejak 2019. Kegiatan ini bertujuan untuk memberikan sebanyak-banyaknya pengalaman belajar menarik dan menyenangkan tentang Bahasa Inggris, Komputer, pembentukan karakter, serta keterampilan dalam manajemen diri sehingga pesertanya dapat berdaya guna dan berdaya saing di tengah-tengah masyarakat.

Smart is an Art terbentuk karena kesadaran bahwa pendidikan nonformal sangat penting untuk mendukung tumbuh kembang anak usia dini dan remaja, bahkan dewasa dalam kesiapan menuju era globalisasi dengan kencangnya persaingan. Smart is an Art adalah juga sebuah motto para penggeraknya bahwa menjadi cerdas itu adalah sebuah seni. Seni untuk menciptakan pembelajaran, seni untuk menerima pembelajaran

Menyaksikan tantangan dunia pendidikan saat ini, Smart is an Art hadir pada RT 006/RW 001 KPR Putra Residence dengan kegiatan berjudul: Membentuk Generasi Muda Melek Baca Dan Teknologi. Kegiatan ini dilatarbelakangi oleh keinginan Tim untuk membantu anak-anak mengenal teknologi komputer dan juga gemar membaca melalui buku-buku yang disediakan oleh Tim. Terdapat 100 buku yang terdiri dari 50 buku bacaan, 5 buku ensiklopedia dan 45 buku referensi pelajaran komputer dan bahasa Inggris.

Adapun tujuan yang ingin dicapai dari pelaksanaan kegiatan ini adalah sebagai berikut:

a. Untuk membantu para peserta memahami pentingnya membaca dan teknologi.

b. Untuk memberikan pembelajaran yang menarik dan menyenangkan.

\section{LANDASAN TEORI}

Dalam pemaparan artikel ini perlu dijelaskan arti kata-kata kunci yang disebutkan sebelumnya, agar setiap pembaca memahami maksud penulisan artikel ini. Adapun arti dari setiap kata kunci tersebut adalah sebagai berikut:

\section{a. Ciri-Ciri Media Belajar}

Ciri - Ciri Pembelajaran menurut Cecep Kustandi (2013:5):

1) Pada proses pembelajaran, guru harus menganggap siswa sebagai individu yang 
mempunyai unsur-unsur dinamis yang dapat berkembang bila disediakan kondisi yang menunjang.

2) Pembelajaran lebih menekankan pada aktivitas siswa karena yang belajar adalah siswa, bukan guru.

3) Pembelajaran merupakan upaya sadar dan sengaja.

4) Pembelajaran bukan kegiatan insidental, tanpa persiapan.

5) Pembelajaran merupakan pemberian bantuan yang memungkinkan siswa dapat belajar.

Dina Indriana (2011:53) menjelaskan ciri-ciri sebuah media pembelajaran adalah:

1) Sesuatu yang menjadi penekanan dalam media pengajaran adalah keperagaan.

2) Media pengajaran merupakan bentuk komunikasi guru dan siswa.

3) Media pengajaran merupakan alat bantu utama dalam mengajar di dalam kelas atau luar kelas.

\section{b. Tujuan Media Pembelajaran}

Tujuan dan manfaat media dalam pembelajaran menurut Azhar Arsyad (2002) sebagi berikut :

1) Media pengajaran dapat memperjelas penyajian pesan dan informasi sehingga dapat memperlancar dan meningkatkan proses dan hasil belajar.

2) Media pengajaran dapat meningkatkan dan mengarahkan perhatian anak sehingga dapat menimbulkan motivasi belajar, interaksi yang lebih langsung antara siswa dan lingkungannya, dan kemungkinan siswa untuk belajar sendiri-sendiri sesuai dengan kemampuan dan minatnya.

3) Media pengajaran dapat mengatasi keterbatasan indera, ruang dan waktu.

4) Media pengajaran dapat memberikan kesamaan pengalaman kepada siswa tentang peristiwa-peristiwa dilingkungan mereka, serta memungkinkan terjadinya interaksi langsung dengan guru, masyarakat, dan lingkungannya misalnya melalui karyawisata, kunjungan ke museum atau kebun binatang. 


\section{c. Manfaat Media Pembelajaran}

Manfaat media menurut Dina Indriana (2011:48) yaitu :

1. Membuat konkret berbagai konsep yang abstrak.

2. Menghadirkan objek yang terlalu berbahaya atau sukar didapat kedalam lingkungan belajar melalui media pengajaran yang menjadi sampel dari objek tersebut.

3. Menampilkan objek yang terlalu besar atau kecil ke dalam ruang pembelajaran pada waktu kelas membahas tentang objek yang besar atau terlalu kecil tersebut.

4. Memperlihatkan gerakan yang terlalu cepat atau lambat.

\section{METODE PELAKSANAAN}

Dalam mengatasi permasalahan yang terjadi pada masyarakat mitra sebagaimana yang telah diuraikan sebelumnya, maka dalam Pengabdian Kepada Masyarakat ini ditawarkan beberapa metoda pendekatan yang dapat membantu dalam menyelesaikan masalah yang ada yaitu dengan melakukan Metode sosialisasi serta pengajaran kepada anak-anak usia dini dan remaja. Kegiatan Pelaksanaan PKM terbagi menjadi tiga tahap, yaitu persiapan, pelaksanaan, dan tahap monitoring. Berikut adalah rincian tiap tahapan yang akan dilaksanakan:

a. Tahap Persiapan

Adapun ada beberapa hal yang dilakukan dalam tahap persiapan sebagai berikut:

1) Penyusunan program kerja sosialisasi dan pengajaran.

2) Penyusunan program sosialisasi dan pengajaran agar kegiatan yang dilaksanakan menjadi lebih teratur dan terarah. Program ini meliputi semua hal-hal yang bersifat teknis, manajerial dan penjadwalan (time schedule).

b. Tahap Pelaksanaan

Tim melakukan penjelasan materi dan sosialisasi kemudian melakukan bentuk-bentuk pengajaran yang melibatkan peserta secara aktif dan menyenangkan.

c. Tahap Monitoring

Tim melaksanakan pemantauan terhadap seluruh proses yang telah dilakukan dan kemudian melakukan evaluasi proses. 


\section{HASIL DAN PEMBAHASAN}

Pelaksanaan kegiatan Smart is An Art diselenggarakan dengan santai dan menyenangkan. Hal ini dibuat dengan tujuan memberikan perasaan rileks tanpa beban belajar bagi para peserta. Kegiatan ini dilaksanakan pada 2 (dua) rumah warga di KPR Putra Residence dengan jumlah 20 peserta. Kegiatan dibuka dengan Doa, penyampaian teknis kegiatan kemudian pemaparan materi. Adapun pemaparan materi adalah praktek pengenalan komputer, tablet dan handphone, serta pengenalan buku- buku bacaan. Pemateri juga membaca cerita, memutarkan video cerita dan evaluasi cerita bersama dengan peserta seperti yang ditampilkan pada gambar berikut.

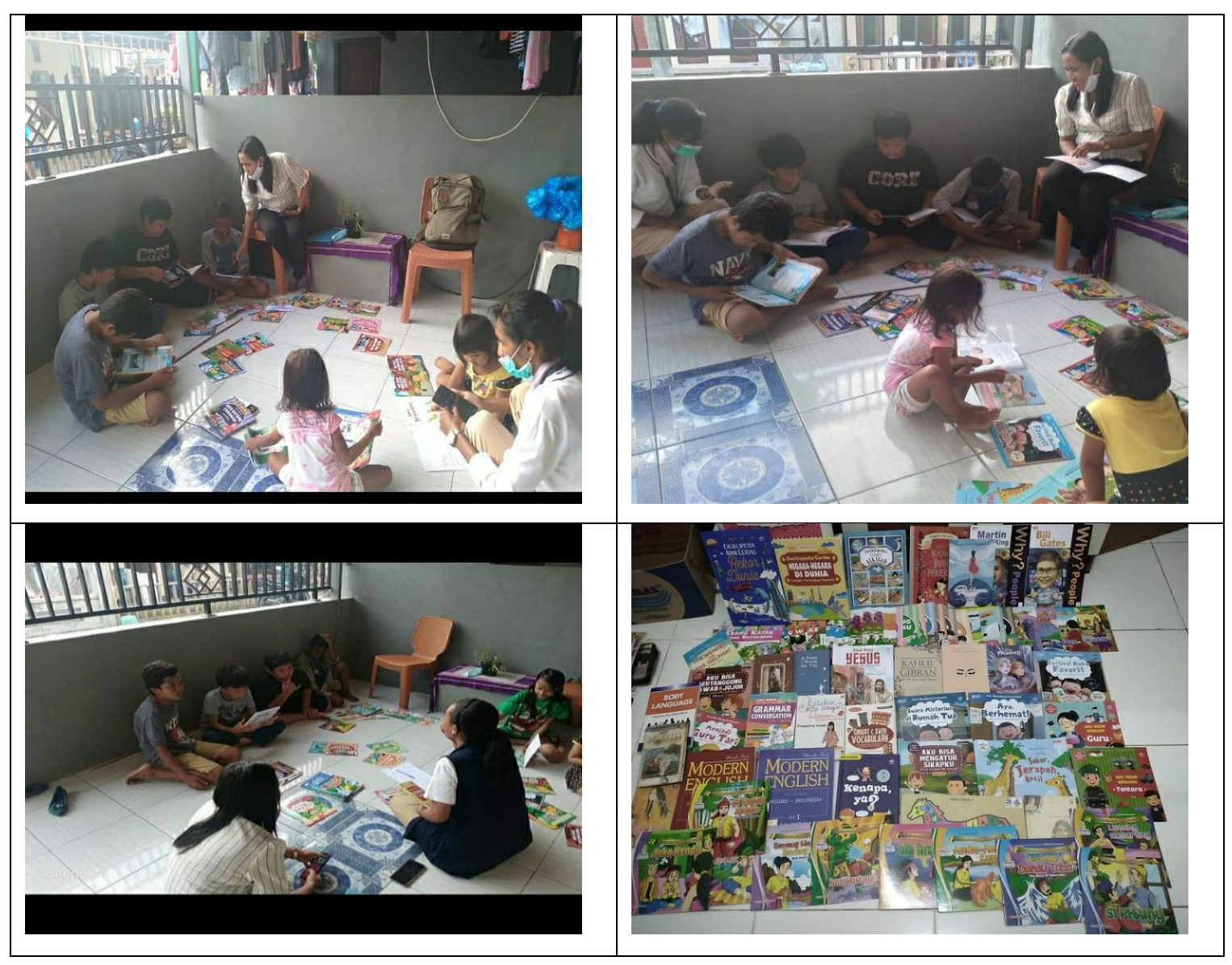



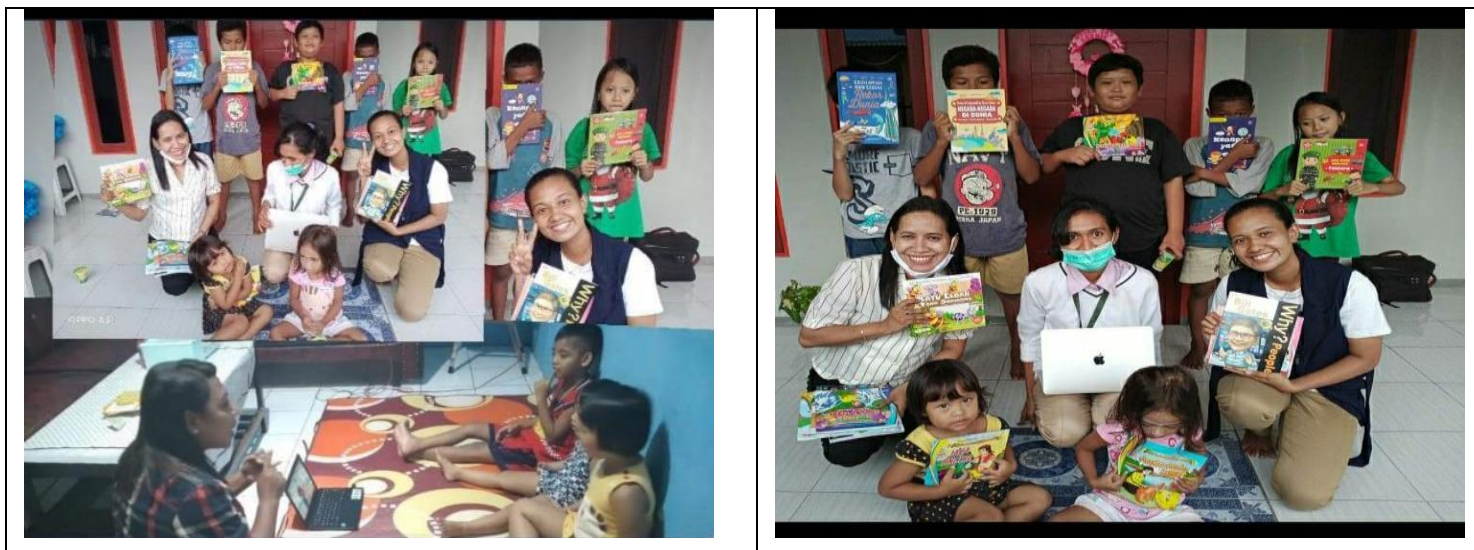

Gambar 1. Pelaksanaan Kegiatan Smart is An Art

Manfaat dari pelaksanaan kegiatan ini adalah untuk melatih peserta disiplin belajar selama masa pandemi, meningkatkan ketertarikan terhadap buku bacaan dan teknologi.

\section{KESIMPULAN}

Kesimpulan dari kegiatan pengabdian kepada masyarakat yang telah dilakukan dan memberikan hasil yang diperoleh peserta adalah sebagai berikut:

a. Dari hasil wawancara dan observasi pada saat pelaksanaan kegiatan didapati hasil bahwa program ini memberikan manfaat yang sangat baik yaitu peserta merasa belajar itu sangat menyenangkan juga bisa mengobati kerinduan pada sekolah.

b. Kegiatan yang telah dilakukan ini meningkatkan kecintaan peserta pada buku bacaan dan teknologi. Adapula yang menyampaikan bahwa bercita-cita menjadi guru, ahli teknologi dan lain sebagainya.

\section{UCAPAN TERIMA KASIH}

Kegiatan pengabdian kepada masyarakat ini terlaksana berkat dukungan dari Ketua dan Perangkat RT 006/RW 001 KPR Putra Residence serta respon masyarakat yang sangat luar biasa partisipatif, sehingga patutlah ucapan terima kasih yang sebesar-besarnya Tim PKM berikan. 


\section{DAFTAR PUSTAKA}

Arsyad, Azhar. 2002. Media Pembelajaran, edisi 1. Jakarta: PT. Raja Grafindo Persada.

Cecep Kustandi. (2013). Media Pembelajaran Manual dan Digital. Jakarta : Ghalia Indonesia

Dina Indriana. (2011). Ragam Alat Bantu Media Pengajaran. Yogyakarta : Diva Press

Ellis, D. H. 1997. Zygomycetes: Chapter 16 In ... Mikrobiologi Pangan 1. PT. Gramedia Pustaka Utama.

Paul Suparno. 1997. Filsafat Konstruktisme dalam Pendidikan. (Yogyakarta: Kanisius), hal 65.

Suharsimi Arikunto. (2010). Prosedur Penelitian Suatu Pendekatan Praktik. Jakarta : Rineka Cipta.

Sugiyono. (2011). Metode Penelitian Kuantitatif Kualitatif dan R \& D. Bandung : Alfabeta.

Tadjab. 1994. Ilmu Jiwa Pendidikan, (Surabaya: Karya Abditama), hal 46-47. 